Goldschmidt 2021 Abstract

https://doi.org/10.7185/gold2021.6462

\section{Is there a specific pollution in sediments of urban stormwater basins?}

\author{
JULIEN COUVIDAT ${ }^{1}$, QIUFANG ZHAN ${ }^{1}$, VINCENT \\ CHATAIN $^{1}$, LAETITIA BACOT ${ }^{2}$, MATHIEU GAUTIER ${ }^{3}$, \\ DAMIEN TEDOLDI ${ }^{1}$, GISLAIN LIPEME-KOUYI ${ }^{1}$, CÉCILE $^{2}$ \\ DELOLME $^{1,4}$ AND THIERRY WINIARSKI $^{5}$
}

${ }^{1}$ Univ Lyon, INSA Lyon

${ }^{2}$ GRAIE

${ }^{3}$ INSAVALOR

${ }^{4}$ ENTPE

${ }^{5}$ Univ Lyon, ENTPE

Presenting Author: julien.couvidat@insa-lyon.fr

Stormwater runoff is increasingly managed in urban zones with retention and infiltration basins. A sediment layer accumulates over time, due to the design of such basins favoring the settling of suspended solids (SS) swept from the watershed. The multiplicity of inorganic and organic contamination sources in urban environments results in polycontaminated runoff water, with trace metals and metalloids and various organic micropollutants (distributed between the particulate and dissolved fractions) likely to accumulate in stormwater sediments. However, concentrations in stormwater runoff present a significant spatiotemporal variability (Daly \& al. 2014), raising the question of a specific contamination signature in stormwater sediments. On the other hand, this sedimentary layer contains many reactive phases, such as Iron or organic matter, sensitive to redox changes and capable of affecting a wide range of processes, including biogeochemical cycles, toxicity and speciation of contaminants. The development of the associated microorganisms also promotes the degradation of certain organic micropollutants, thus playing a "self-purifying" role (Lundy \& al. 2012). Operationally, sediment excavation is a common practice to avoid clogging and to ensure the proper functioning of stormwater management facilities but the solutions for the treatment and/or valorization of these deposits still need deeper investigation. Facing the poor understanding of sediment composition and reactivity, practitioners have few other solutions than dealing with ultimate wastes for stormwater sediments.

19 sites of stormwater management facilities (infiltration and retention basins) around Lyon (France) were chosen and investigated for total content analysis, physicochemical properties and reactivity. The analysis of the reactivity, as well as the temporal and spatial variability of the contamination, emphasizes the "integrative" role of the sediments towards contaminants. This fine-grained sedimentary layer, highly organic and polycontaminated, globally reflects the anthropic activities of the watershed (Fig. 1), bringing out the specificity of these sediments generated by a highly anthropized and impermeable urban environment.

\section{References:}

Daly \& al. (2014), Adv Wat Pol

Lundy \& al. (2012), Water Res

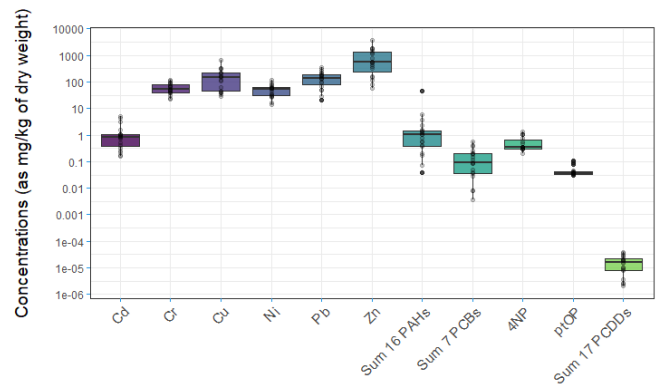

Fig. 1: Trace metals and organic micropollutants analyzed in 19 infiltration basins (4NP $=4$ nonylphenol, ptop = para-ter-octylphénol) 